\title{
Lekcja retoryki doktora Markolfa. Uwagi na temat oralności i piśmienności w kulturze staropolskiej (na przykładzie dzieła Jana z Koszyczek)
}

Poniższe uwagi wiążą się z przekonaniem, że literatura staropolska nie stanowi obszaru badawczego, który został już całkowicie wyeksploatowany, dociekania zaś nad piśmiennictwem dawnym nie zmierzają w stronę analitycznej reprodukcji sensów. Wręcz przeciwnie, każdy, kto interesuje się kulturą polską XVI-XVII wieku, dostrzega z pewnością konieczność przeprowadzenia podstawowych operacji badawczych w odniesieniu do wielu wartościowych tekstów - do takich prymarnych potrzeb należałaby z pewnością praktyka edytorska, ale również świadomość interpretacyjna. Dzięki nim analizowane dzieła mogłyby zyskać odpowiedni kontekst kulturowy ${ }^{1}$. Niestety, w rzeczywistości historycy literatury dawnej obracają się wciąż w kręgu tych samych dzieł i tych samych narzędzi badawczych. Zatem spostrzeżenia te zostały również zainspirowane przeświadczeniem, iż piśmiennictwo dawne powinno być poddane oglądowi, który uwzględniłby dyrektywy badawcze wypracowane przez tzw. metodologie ponowoczesne (np. poetykę kulturową Stephena Greenblatta lub dekonstrukcjonizm Paula de Mana). Przy czym zastosowanie owych reguł zmierzałoby nie tyle do źródłowej weryfikacji samych metodologii, ile do próby nowego spojrzenia na teksty staropolskie. Wydaje się, że podobną szansę stwarza poszukiwa-

\footnotetext{
Przykładem takiej zapoznanej historycznoliterackiej strefy jest piśmiennictwo okolicznościowe, a także literatura popularna.
} 
nie w literaturze dawnej śladów kultury oralnej i towarzysząca temu poszukiwaniu obserwacja przekształcania form piśmiennych w literackie.

Pierwszą przeszkodą utrudniającą dotarcie do śladów kultury oralnej w dziełach dawnych jest — paradoksalnie — sam tekst. I nie chodzi tylko o nieusuwalną sprzeczność warsztatową, polegającą na badaniu pozostałości, a więc rodzaju cywilizacyjnych artefaktów. Jak pisał Eric Alfred Havelock: „[...] gdy pochodzący z piśmiennej kultury badacz sięga po te zasoby [...], wszystko, co ma do dyspozycji, to resztki, historyjki, piosenki i anegdotki, służące już tylko rozrywce i nieprzekazujące żadnych istotnych treści" ${ }^{2}$. Problem polegałby tu na niebezpiecznym zniekształceniu tekstu powstającym na etapie opracowania edytorskiego — jest bowiem kwestią oczywistą, że nawet najlepiej przygotowana edycja krytyczna stanowi tak naprawdę wariację wydawcy na temat dzieła i nie odzwierciedla w pełni jego realnego kształtu. Istnieje uzasadniona obawa, iż elementy ważne dla poszukiwań badawczych zostaną usunięte lub zmodyfikowane w trakcie, skądinąd naukowego, opracowania (w tym wypadku transkrypcji). Zatem rejestracja śladów kultury oralnej powinna uwzględniać rzeczywiste źródła skonfrontowane z edycjami krytycznymi. Praktyka ta nosiłaby bardziej cechy działań dokumentacyjnych niż popularyzacyjnych.

Drugie zagadnienie związane jest z problematyką stylu. Literaturze polskiej praktycznie od samego początku towarzyszy ten aspekt funkcjonowania dzieła. Najlepszym przykładem byłaby tu świecka liryka XV wieku, zachowana szczątkowo i dzięki temu wskazująca bezsprzecznie na występowanie pewnych strategii stylizacyjnych. Mowa tu o dwóch tekstach, a mianowicie o wierszowanym liście miłosnym (inc. „W jedności, stałości serca mego...”), reprezentującym wzorzec miłości dwornej, oraz o tzw. Cantilenae inhonestae (inc. „Chcy ja na pannu żałować...”), należącej do nurtu literatury popularnej ${ }^{3}$. W przypadku tak oczywistych różnic stylu, badacz poszukujący pozostałości kultury oralnej intuicyjnie zwróci się raczej w stronę tekstu popularnego, funkcjonuje bowiem osobliwe przekonanie, że to, co pierwotniejsze, musi być zarazem prostsze $s c$. nieprzetworzone (również z punktu widzenia języka). To chyba niezbyt uzasadnione stanowisko usuwa z pola widze-

2 E. A. Havelock, Muza uczy się pisać. Rozważania o oralności i piśmienności w kulturze Zachodu, przeł. P. Majewski, Warszawa 2006, s. 64.

3 Wiersze znalazły się w edycji: Polska poezja świecka XV wieku, oprac. M. Włodarski, Wrocław 1997 (BN I, 60), s. 97-108. 
nia teksty, które — wbrew przynależności do stylu wysokiego — posiadają elementy będące przedmiotem badawczego zainteresowania. Należy przecież pamiętać, że stylistyka dawała częstokroć impuls do głębszej refleksji nad kwestią relacji pomiędzy oralnością a piśmiennością ${ }^{4}$. Ewidencja śladów kultury oralnej powinna więc uwzględnić wszystkie dostępne obecnie teksty staropolskie, nie zaś wyłącznie te tradycyjnie kojarzone np. z nurtem piśmiennictwa popularnego.

Z problematyką stylu łączą się dodatkowo dwa inne obszary badawcze: genologia oraz paremiografia. Autorzy dawnych dzieł dość ściśle przestrzegali dyrektyw poetyki wiążących styl z określonym gatunkiem — niejednokrotnie trudno jest oderwać jedną płaszczyznę od drugiej i dodatkowo wskazać hierarchię ważności lub kierunek inspiracji ${ }^{5}$. Wymagałoby to prześledzenia poetyk — w tym również zachowanych w rękopisach traktatów — z punktu widzenia łączliwości stylów i gatunków, konfrontacji z zagadnieniem relacji oralne / piśmienne, a ponadto rejestracji utworów albo fragmentów utworów, w których dochodzi do rozszczepienia tych perspektyw. Z drugiej zaś strony należałoby zastanowić się nad stopniem przekształcenia przysłów włączonych w dyskurs poetycki. Istnieją bowiem formuły, charakterystyczne głównie dla epigramatyki i sankcjonujące pewne twierdzenia jako elementy wspólnotowej praktyki intelektualnej (np. frazy typu: „Mówią, że...”; „Jako powiadają...”). Nie ma jednak pewności, co do rzeczywistego stopnia przynależności tych twierdzeń do skarbnicy społecznych doświadczeń, ustalenie zaś hierarchii źródłowej jest niemal niemożliwe ${ }^{6}$, choć jednocześnie wszelkie tego typu formuły trzeba traktować jako sygnały świadomości warsztatowej (literackiej). Pewnego zastanowienia wymagałyby również te sytuacje, w których dany fragment tekstu poetyckiego spełnia formalne lub stylistyczne wymogi przysłowia, natomiast nie pojawia się w literaturze paremiograficznej, bądź też występuje tam w odmiennej wersji. W każdym razie paremiografia (ze względu

\footnotetext{
4 Por. E. A. Havelock, op. cit., s. 27, 72 (uczony posłużył się tu pojęciem „styl oralny").

5 Badacz musiałby tu określić, czy konkretny element tekstu jest w istocie śladem kultury oralnej, czy też stanowi on funkcję stylu, zdeterminowaną z kolei przez przynależność gatunkową dzieła. Dodać trzeba także, że płaszczyzny te nie muszą się wzajemnie wykluczać.

6 Trudność polega tutaj na przyjęciu właściwej metody weryfikacyjnej — nie wolno wszak zapominać, że Nowa Księga Przystów Polskich pod redakcją Juliana Krzyżanowskiego została opracowana również z wykorzystaniem materiału literackiego.
} 
na skojarzenia z folklorystyką znalazła się ona w ostatnich latach na marginesie badań historycznoliterackich nad kulturą dawna) powinna stać się tu przedmiotem uważniejszego oglądu.

Trzecim - najistotniejszym z punktu widzenia precyzji naukowej — zagadnieniem jest kwestia terminologii. Wydaje się, że pojęcia stosowane w pracach nad kulturą oralną lub jej pozostałościami w kulturze piśmiennej charakteryzują się dość dużą rozciągłością znaczeniową, w związku z czym mogą być stosowane do analizy zjawisk niezwiązanych pierwotnie z zakresem, do których się odnosiły. Dobrym przykładem byłaby tu klasyczna pozycja autorstwa Waltera Jacksona Onga ${ }^{7}$. Pojawia się w niej np. termin redundancja w znaczeniu obfitości, czyli powtarzalnego nagromadzenia wiedzy. Trudno w takim przypadku, choćby intuicyjnie, nie odwołać się do perspektywy retorycznej, nawet w wymiarze historycznym, nie zaś komunikacyjnym. Chodziłoby tu zatem o uwzględnienie kontekstu terminologii oratorskiej i oddzielenie sfery oralności, a tym bardziej oralności wtórnej, od problematyki kultury retorycznej XVI-XVII wieku.

Wskazane wyżej zagadnienia stanowią jedynie wstępne rozpoznanie problematyki, towarzyszącej lekturze dzieła będącego — wedle mojego rozumienia - ciekawym śladem napięć pomiędzy kulturą oralną i piśmienną, a mianowicie Rozmów, które miat król Salomon mądry z Marchottem grubym a sprosnym Jana z Koszyczek.

Polska wersja tekstu powstała przed 17 grudnia 1521 roku. Na precyzyjną datę wskazuje przedmowa wydawcy — Hieronima Wietora. Przedmowa została zaadresowana do Anny z Jarosławskich Jordanowej, żony zarządcy dóbr królewskich, Mikołaja Jordana ${ }^{8}$. Treść słowa wstępnego nie ma większego znaczenia dla rozpatrywanych tu kwestii, natomiast samo jego pojawienie się jest niezwykle ważne. Dzięki niemu bowiem polski tekst zostaje osadzony w charakterystycznej dla kultury renesansu strukturze książki drukowanej obejmującej tzw. dodatkowe cząstki konstrukcyjne dzieła, a więc np. listy dedykacyjne, wiersze dedykacyjne, informacje ściśle wydawnicze, odnoszące się do funkcjonowania oficyny drukarskiej itd. Co więcej, przedmowa wraz z dwoma wierszami zamy-

Por. W. J. Ong, Oralność i piśmienność. Stowo poddane technologii, przeł. J. Japola, Lublin 1992.

8 Zob. Jan z Koszyczek, Rozmowy, które miat król Salomon madry z Marchottem grubym a sprośnym, w: Proza polska wczesnego renesansu, oprac. J. Krzyżanowski, Warszawa 1954, s. 85-86. Wszystkie cytaty pochodzą z tej edycji. 
kającymi (Upominanie do czciciela oraz Przemowa do Polaków) ${ }^{9}$ tworzy ramę wydawniczą, w której ujawniają się istotne elementy świadomości warsztatowej wczesnorenesansowego twórcy oraz jego nakładcy.

Pierwodruk Rozmów... zachował się tylko częściowo - jego współczesne wydanie składa się z trzech obszernych fragmentów zaczerpniętych z różnych XVI-wiecznych edycji, wszelkie zaś braki wydawca uzupełnił tłumaczeniem z łaciny własnego autorstwa. Dwa fragmenty mają charakter narracyjny, fragment zaś pierwszy jest niemal w całości dialogiem dwóch głównych bohaterów dzieła:

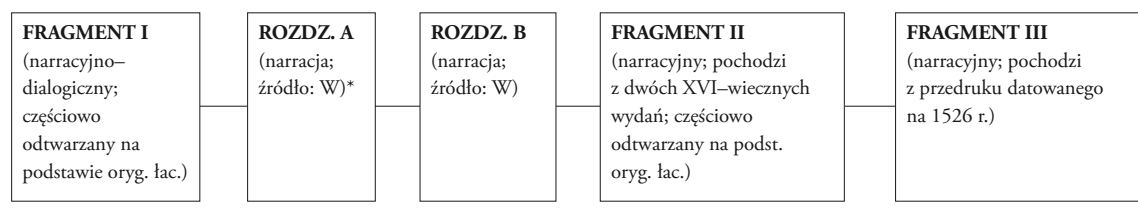

$\left({ }^{*} \mathrm{~W} \text { - Wokabularz rozmaitych sentencyj, liczne wydania w latach } 1539-1641\right)^{10}$

„Dialogiczność" tekstu została podkreślona w tytule oryginału Disputationes quas dicuntur habuisse inter se mutuo rex Salomon sapientissimus et Marcolphus, facie deformis et turpissimus, tamen ut fertur eloquentissimus. Widać zatem natychmiast, że obie postaci reprezentują tu dwa odrębne porządki - prawdziwą mądrość o zabarwieniu sakralnym (Salomon sapientissimus) oraz biegłość retoryczną, pewien typ chłopskiego sprytu (Marcolphus eloquentissimus):

Salomon rzekł: Rozumnie czynisz wszystko, Marchołcie!

Marchołt: Nie jest ci to rozum, lecz co z chytrości zwierzyłem siostrze mojej, powiedziała zdradziecko, jak gdyby to była prawda. ${ }^{11}$

Te same elementy charakterystyki obu bohaterów tekstu zostały usankcjonowane i potwierdzone w dwóch odrębnych genealogiach rodowych biblijnej w przypadku Salomona oraz skonstruowanej analogicznie, barwnej słowotwórczo, chłopskiej liście przodków Marchołta oraz jego żony.

Wprowadzona już przez tytuł relacja będzie naturalnie kontynuowana w dziele — sytuację dysputy aranżuje sam władca, Marchołt zaś

9 Por. ibidem, s. 120.

10 Schemat rekonstrukcji utworu został sporządzony na podstawie cytowanej edycji w oprac. J. Krzyżanowskiego.

11 Ibidem, s. 107-108. 
znajduje możliwość artykulacji tylko i wyłącznie poprzez wpisanie się w porządek ustanowiony przez króla. Marchołt istnieje tylko jako odpowiedź na kwestie Salomona. Układ ten powoduje, że w literaturze przedmiotu Marchołta identyfikuje się jako figurę błazna, natomiast całe dzieło tłumaczone przez Jana z Koszyczek zalicza się do nurtu literatury błazeńskiej ${ }^{12}$. Mówiąc nieco inaczej, Marchołt dokonuje przekładu prawd wypowiadanych przez Salomona, werbalizuje mądrość króla odmiennym językiem. Jak pisał Michał Głowiński: „Gesty marchołtyczne nie ograniczają się zresztą do działań [...], ich odrębną dziedziną jest mówienie" ${ }^{13}$. Marchołt to po prostu język.

Wydaje się wobec tego uzasadnione, aby w polskim tekście Jana z Koszyczek doszukiwać się śladów relacji pomiędzy elementami kultury oralnej a elementami kultury pisma. Każda kwestia wypowiadana przez Salomona znajduje wszak odpowiedź w postaci Marchołtowego porzekadła. Zasadniczy problem polegałby tu jednak na drobiazgowej analizie stopnia spójności poszczególnych sekwencji dialogicznych. Bywają bowiem sytuacje, w których odpowiedź Marchołta zdaje się nie mieć związku z sentencją Salomona, w innych wypadkach można zauważyć ewidentne zbieżności, a wreszcie — szereg kwestii tworzy $\mathrm{w}$ istocie dwugłosowe sekwencje, np.:

\section{Poziom I:}

Salomon: Dobra niewiasta a cudna jest okrasa mężowi swemu.

Marchołt: Garniec mleka napełniony dobrze ma być przed kotką strzeżony.

Poziom II:

Salomon: Polepszmy się z tego, cochmy niewiadomie zgrzeszyli.

Marchołt: Kiedy ty dupę ucierasz, zaż co inego w ten czas działasz?

Poziom III:

Salomon: Odpowiedaj głupiemu podług jego głupości, aby go nie miano za mądrego.

Marchołt: Co opoka usłyszała, to dębowi powiedała. ${ }^{14}$

12 Por. M. Głowiński, Portret Marchotta, w: Mity przebrane. Dionizos - Narcyz Prometeusz - Marchott — Labirynt, Kraków 1994, s. 115-120; J. Ziomek, Literatura btazeńska. "Marchott” i „Sowizdrzat”, w: Id., Renesans, Warszawa 1995, s. 144-145.

13 M. Głowiński, op. cit., s. 128.

14 Jan z Koszyczek, op. cit., passim. 
Ponieważ całym dziełem rządzi strategia parodii i przesunięcia Salomona ze sfery kultury wysokiej do niskiej, najciekawszym owocem zastosowania retoryki Marchołta jest efekt rozwarstwienia sensu, w którego horyzoncie rysują się ślady kultury oralnej.

Napięcie między sferą oralną a piśmienną ujawnia się także we wspomnianej już ramie wydawniczej dzieła. Polski tytuł odzwierciedla nie tylko kształt łacińskiego oryginału, ale także dodatkowo wyposaża tekst w formułę wspólnotową - Rozmowy, które miat król Salomon mądry $z$ Marchottem grubym a sprosnym, a wszakoż jako o nim powiedaja $q^{15}$, barzo z wymownym, z figurami $i$ z gadkami śmiesznymi. Konfrontacja dwóch modeli mądrości zakłada jednocześnie unaocznienie wartości doświadczenia rzeczywistego — jak pisał Kazimierz Budzyk: „więcej niż połowa replik Marchołta zmierza do tego, by abstrakcyjnej, nieużytecznej mądrości króla przeciwstawić mądrość życiową, płynącą z praktyki” ${ }^{16}$. W Upominaniu do czczciciela powiada się wprost: „Ty jego [Marchołta] ${ }^{17}$ kunszty pamiętaj" (w. 4) ${ }^{18}$. Zarazem jednak Marchołtowa sztuka retoryki zdradza wyraziste związki z kulturą pisma:

Salomon: Cudna rzecz jest biały czepiec na głowie niewieściej.

Marchołt odpowiedział: P is a n o jest: Nie są takie rękawy jako kożuch cały.

Często pod białym czepcem bywa mól niemały. ${ }^{19}$

Potrzeba pamięci i nauki, podkreślona w przywołanym przed momentem wierszu ramowym, zyskuje jednak nieco inny wymiar praktyczny:

Ty, co ku czcieniu masz chciwość,

Weźm Marchołta przed obliczność.

Kupuj chciwie, a przeczytaj,

15 Jeśli nie zaznaczono inaczej, wszystkie podkreślenia w tekstach źródłowych pochodzą od Autora artykułu.

16 K. Budzyk, „Marchott” Jana z Koszyczek, w: Ze studiów nad literatura staropolska, Wrocław 1957, s. 87. Cyt. za: S. Grzeszczuk, Btazeńskie zwierciadto. Rzecz o humorystyce sowizdrzalskiej XVI i XVII wieku, Kraków 1994, s. 221.

17 Jeśli nie zaznaczono inaczej, wszystkie komentarze w tekstach źródłowych pochodzą od Autora artykułu.

18 Jan z Koszyczek, op. cit., s. 120.

19 Ibidem, s. 90. 
Ty jego kunszty pamiętaj.

(Upominanie do czciciela, w. 1-4) ${ }^{20}$

Ostatecznie zaś w zamknięciu dzieła ujawnia się charakterystyczne dla kultury renesansowej przekonanie o prymarnej roli pisma i druku w procesie kształtowania się świadomości intelektualnej:

Za wam miło błazeństwo to będzie ku czcieniu,

Ku biegłości rozumu i ku ubaczeniu.

To baczcie, iż biegłość rozumu z pisma pochodzi,

A pismo proste ludzi k rozumu przywodzi.

(Przemowa do Polaków, w. 5-8) ${ }^{21}$

Właśnie owo połączenie elementów kultury słowa i kultury pisma (druku) świadczy o badawczym potencjale literatury dawnej, szczególnie zaś tych staropolskich tekstów, których — wydawałoby się — ze względu na ich tradycyjnie ustalone miejsce w hierarchii zjawisk historycznoliterackich, nie sposób już inaczej interpretować ${ }^{22}$.

\section{Doctor Markolf's Lesson on Rhetoric. Notes on Orality and Literacy in Old Polish Culture (Based on the Example of Joannes de Coszycze's work)}

The origin of this draft is associated with the conviction that Old Polish literature as a research area had not been totally exploited and inquiry into old literacy does not tend toward the reproduction of analytical meanings. In practice, however, literary historians dealing with old literature continue to work within a circle of the same works, using the same research tools. It seems that the opportunity for "renewal of meaning" would attempt to seek evidence in the literature of ancient oral culture, accompanied by the observation of the transformation of forms of writing into forms of literary writing.

The above issue is an initial diagnosis of the problem, accompanying the reading of the work which traces an interesting tension between oral and literate

20 Ibidem, s. 120.

21 Ibidem.

22 Chodziłoby tu, naturalnie, o interpretacje komplementarne, uzupełniające, wzbogacające wiedzę na temat literatury i kultury dawnej. 
culture, namely Rozmowy, które miat król Salomon mądry z Marchottem grubym a sprosnym by Joannes de Coszycze. This combination of elements of culture of the word and culture of writing (print) evidence of research potential of the old literature, especially the Old Polish texts, which, seemingly, because of their long-established place in the hierarchy of literary history phenomena, can no longer be interpreted differently. The Polish version of the dialogue between Marchołt and Salomon belongs to this group.

Translated by Agnieszka White 